\title{
The application of Nuo culture elements in modern dress design, Based on the example of Nanfeng County in Jiangxi
}

\author{
Dong Yalin
}

Nanchang Institute of Science \& Technology, Nanchang 330108,China

Key words: Clothing design; modern design; aesthetic standards; Nanfeng County; Nuo culture

\begin{abstract}
In the fashion design process, especially in modern dress design, there are often a lot of problems in the use of traditional folk culture, which is because in the fashion design process and no field trips to a traditional culture but no real meaning will interpret out of context, the use of modern aesthetic standard in fashion design. In order to study the use of Nuo culture elements in the modern fashion design, taking Nanfeng County as an example. As for the clothing of modern analysis, it discusses the importance of integration of Nuo culture in modern clothing design process. Finally it puts forward Nuo cultural elements into modern clothing design method, which provides a new idea for study of Nuo culture and modern fashion design.
\end{abstract}

\section{Introduction}

Jiangxi is an important distribution area of China Nuo culture, Nuo culture in the history of Jiangxi long deposition in its complete system of renowned domestic provinces, Nuo opera, Nuo culture, Nuo and Nuo temple architecture, has rich in characteristics of Nuo culture group. Nanfeng, Pingxiang has been occupied by the Ministry of Culture named "Nuo" township, Nanfeng County clear preserved Nuo culture since the early years of the Western Han Dynasty since ancient civilization heritage mark, a record of this cultural phenomenon through changes in the traces of years of circulation. Through the study of Nanfeng County of Nuo culture elements, which can be based on analysis of effects of cultural elements on the clothes, into the modern fashion design elements, designed to meet modern fashion concept and with the visual impact of the modern clothing.

\section{The characteristics of Nuo culture costumes in Nanfeng County}

Nuo culture has a history of thousands of years, after such a long time, Nanfeng Nuo dance clothing has reached a mature state, on the basis of some traditional modelling, also developed some new styling and technology, so as to make simple dress, with modern flavor. In the modeling, based on dress vest, robe and cardigans greatly on the launch of a number of modern fashion elements, and the manufacturing industry and modern printing technology combined with embroidery, with this process, clothing has some modern flavor in color and shape, brought a striking visual impact to clothing. 


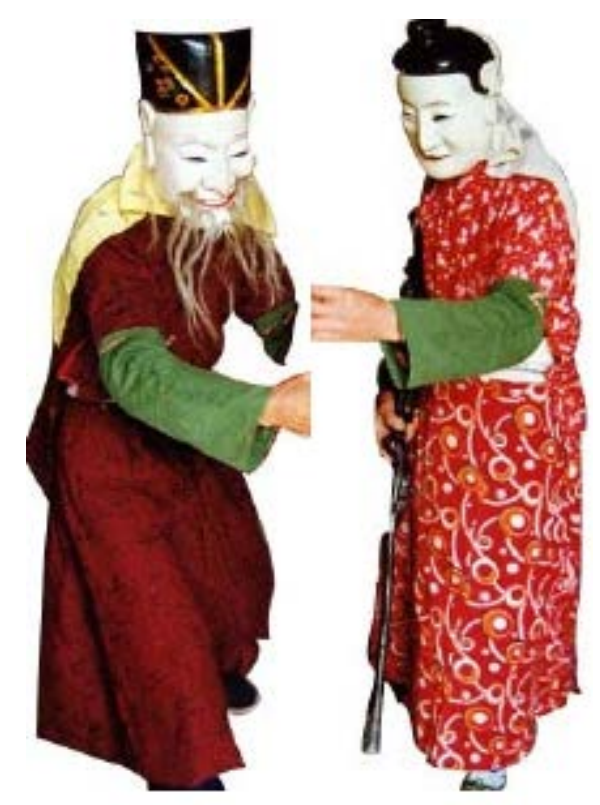

Fig.1 Nuo culture, costume in Nanfeng village, Nuo village

Figure 1 is the dress of Nuo culture researcher Wang Hanyun in research Shiyou village Nanfeng County clothing pictures, as shown in Figure 1, Shiyou children jump when the exorcism dance form, in front of the blouse tucked inside a waist skirt, left on the skirt, dress with traditional cultural elements, but also into the present generation of breath.

\section{The cultural elements will melt into the meaning of modern clothing}

First of all, from the clothing style and visual impact, although the ancient Nuo clothing bold, but also the modern personality in the exquisite, simple appearance is also rich in gorgeous, it has certain enlightenment for modern dress design, because in the modern fashion design process, we only pay attention to gorgeous appearance, clothing to ignore the connotation, personality and practicality etc.. Especially the personality characteristics of clothing in particular personality, different people wearing different clothes will show their own characteristics, and China dress also differs from other countries, must have their own characteristics, and thousands of years of Nuo culture is a carrier that is.

Secondly Chinese thousand years of history, is a famous ancient cultural history, and this is also a part of Nuo culture in history, is the one and only, with obvious characteristics, if the Nuo culture and modern fashion design elements combined with the domestic and foreign modern clothing design idea into Nuo culture of fashion design that is a perfect western merger, achieve the global development strategy of modern fashion design. With the development of modern communication technology, the mobile phone WeChat, micro-blog and various communication terminal ", Nuo culture once the promotion, will be attention quickly, and Nuo culture concept design clothing, also will certainly be favored, if will promote the integration of Nuo culture and costume design concept, will have broad market prospects.

To integrate Nuo culture into modern fashion design, the most important thing is to integrate its cultural connotation. We know that the highest realm of costume design is beauty outside, and show in the inside, this is the boutique in the boutique. The connotation of Nuo culture itself is a kind of flexible empty spirit, there is a fear to gods and the beauty of connotation indeed warm and simple and solemn, with the hope of beauty, if the connotation to the modern fashion design, and the use of flexible, will develop a lot of good clothing. 


\section{Modern clothing cultural elements into the design of spreading method}

Jiangxi's "booth culture" is part of China's "booth culture", which has a long history and is more original and rich, and enjoys a good reputation both at home and abroad. If the ancient Nuo culture elements into the rich modern garment design process, and the modern aesthetic standards will inevitably collide more sparks, visual impact of the clothing is more, the old things and streamline apparel combination will lead to a fashion trend, we mainly through the two aspects of integration the Nuo culture to modernization in costume design.

The integrate into the form beauty of Nuo culture.China's traditional culture and exquisite artistic beauty, harmonious beauty of God and the shape of the artistic conception, has distinct national and regional costume design Chinese, but these are unified obviously, that is the cultural and artistic elements. Clothing design is the design of the soul, is a clothing design specification and the spirit, and the spirit and norms of Nuo culture and there are many similarities, Nuo culture is a particular ideology, as the Confucian culture, is a kind of feudal ideology and culture, and Nuo culture is plain farmland in ancient China the cultivation of class consciousness, have the beauty of form is obvious, if the elements of a perfect expression in the fashion design process, will be given more beauty to clothing.

The integrate into the emotion of Nuo culture.In the modern fashion design concept, aesthetic characteristics and functional clothing is the two most important elements, but with the concept of traditional culture is gradually broken, people for the pursuit of clothing is no longer the external formal beauty is simple, but the function of clothing and clothing unique emotion expression.

The concept of Nuo culture in the design of clothing, can not only consider the beautiful shape, but more to consider the beauty of God, such as Jiangxi Nuo opera clothing as an example, this kind of clothing will be rough and lead a fast in the design, but this is the expression of young people to chase the symbol of ideal enthusiasm. Then, the costumes are very meaningful, because we know that "stalls" have "shock driving fierce ghost", it is difficult to avoid the meaning of its people. The Nuo culture itself has a symbol of protection against evil spirits, so some features in the clothing design can give fashion, such as your God, God beauty this design philosophy and modern fashion design is similar.

In modern fashion design, if we integrate into Nuo culture, we can not simply copy it, thus losing the charm of Nuo culture. In recent years, many garment design also tried, but in the end is tasted, simply put into the Chinese taste while ignoring the emotional expression, therefore, is give up halfway. So we have Nuo culture into modern fashion design process, need to study the basis of Nuo culture, life and field investigation in Jiangxi, especially the Nuo culture rich in Nanfeng County, the affective factors into the nation's local customs and practices in clothing design, the Nuo culture charm show perfect in fashion design in.

\section{Conclusion}

In order to study the use of Jiangxi Nuo culture in modern clothing design, it proposes for the production of clothing based Nanfeng Nuo dance, Nuo culture of modern modeling and process analysis, and discusses the Nuo culture into modern fashion design, the Nuo culture into methods in modern fashion design. With the "Nuo culture hot wind intensified, Nanfeng Nuo by national, provincial and municipal departments attach great importance to culture, gradually around the Nuo culture exchange exchange performance, clothing Nanfeng Nuo dance has entered a new period of its development. Therefore, in the modern fashion design, you can consider more personalized 
cultural factors into the clothing design, so that clothing can express personalized emotional factors, and increase the connotation of clothing beauty.

\section{Acknowledgement}

The work was supported by the general project of art planning project in Jiangxi with the project number YG2015087 and the project name The application of Nuo culture elements in modern dress design Based the example of Nanfeng County in Jiangxi.And the topic direction is Investigation and analysis of artistic characteristics and charm of Nuo culture in Nanfeng County.

\section{Reference}

[1] ZengXia, JinZhi. The clothing CAD application:The advantages and disadvantages of the study [J]. Journal of Yulin Normal University, 2012 (05).

[2] Zhao Baosheng. Excel application skills. [J]. digital technology and applications,2012 (07).

[3] Sun Li. Application and existing problems of clothing CAD [J]. Public Technology,2010 (11).

[4] He Guiliang, Dai Hong. Study on current situation and development of CAD/CAM usage in clothing industry [J]. Hebei textile, 2008 (02).

[5] Zhu Guangzhou. Popularization and application of clothing [J]. CAD knitting industry,2007 (08).

[6] Zhang Qize, Huang Fang. Analysis of development and application of domestic clothing CAD technology [J]. Guangxi textile technology, 2007 (01).

[7] Jiao Huiqin, Feng Wei Yi, Zhang Yunpeng. Research on the application of SVG in clothing design system [J]. Silk,2007 (01),

[8] Zhang Doujuan, Chen Cunyuan. Excel macro in the application of statistical reserves parameters [J]. Logging Technology,2006 (06).

[9] Zhang Jun, Du Peng. Research and application of PostScript technology,[J]. Electronic Science and Technology,2003 (01).

[10] Dong Ge. Study on the defect texture in fabric design [J]. Art and Design (Theory), 2009 (08).

[11] Wang Mei, Lu Guodong, Zhang Dongliang. Research and application of 3D human modeling technology in garment [J].Journal of engineering graphics,2007 (01).

[12] Ke Huiling. Art fashion renderings, [J]. Art\&Life,2006 (05).

[13] Teng Xiaobo, Su bin. From New Media Art to Information Art- Interview with Prof. Lu Xiaobo[J]. Decoration,2004 (12).

[14] XiangGan. Characteristics, forms and performance techniques of costume CAD painting[J]. Journal of Wenzhou Vocational and Technical College,2004 (02).

[15] Wang Qiming. Analysis of the methods and current situation of 3D human body measurement in apparel industry [J]. Journal of Shaoxing University (NATURAL SCIENCE),2002 (10) .

[16] Luo Shunhua. Application of visual art in fabric design [J]. International textile Herald,2007 (09). 